\title{
Release Mechanism and Kinetic Models of Gypsum-Sulfur-Zeolite Coated Urea Sealed with Microcrystalline Wax for Regulated Dissolution
}

Farahnaz Eghbali Babadi ${ }^{\dagger}$, Robiah Yunus ${ }^{\ddagger}$, Salman Masoudi Soltani ${ }^{\S}$, Artiwan Shotipruk ${ }^{\dagger}, *$

$\dagger^{\dagger}$ Bio-Circular-Green-economy Technology \& Engineering Center, BCGeTEC, Department of Chemical Engineering, Faculty of Engineering, Chulalongkorn University, Phayathai Road, Bangkok 10330, Thailand

$\ddagger$ Department of Chemical and Environmental Engineering, Faculty of Engineering, Universiti Putra Malaysia, Selangor 43400, Malaysia

$\S$ Department of Chemical Engineering, Brunel University London, UB8 3PH Uxbridge, United Kingdom 


\section{Supporting data}

Table S1: Release of nitrogen content from uncoated urea and commercial sulpfur-coated urea (SCU) determined by the HPLC method and the Kjeldahl method

\begin{tabular}{|c|c|c|c|c|c|c|c|c|c|c|c|c|c|c|c|c|c|c|}
\hline \multirow{2}{*}{ Sample } & \multirow[t]{2}{*}{ Methods } & \multicolumn{17}{|c|}{ N (\%) } \\
\hline & & $0 \mathrm{~h}$ & $1 \mathrm{~h}$ & $3 \mathrm{~h}$ & $5 \mathrm{~h}$ & $8 \mathrm{~h}$ & $12 \mathrm{~h}$ & $18 \mathrm{~h}$ & $24 \mathrm{~h}$ & $30 \mathrm{~h}$ & $48 \mathrm{~h}$ & $72 \mathrm{~h}$ & $120 \mathrm{~h}$ & $144 \mathrm{~h}$ & $168 \mathrm{~h}$ & $240 \mathrm{~h}$ & $288 \mathrm{~h}$ & $336 \mathrm{~h}$ \\
\hline \multirow{2}{*}{$\begin{array}{l}\text { Uncoated } \\
\text { urea }\end{array}$} & $\begin{array}{l}\text { Kjeldahl } \\
\text { method }\end{array}$ & $45.8 \pm 0.6$ & $35.54 \pm 0.9$ & $26.8 \pm 0.8$ & $19.7 \pm 0.5$ & $13.6 \pm 0.7$ & $5.9 \pm 0.1$ & $0.78 \pm 0.05$ & $0.04 \pm 0.02$ & & & & & & & & & \\
\hline & $\begin{array}{c}\text { HPLC } \\
\text { method }\end{array}$ & $46.05 \pm 0.01$ & $36.06 \pm 0.05$ & $27.19 \pm 0.02$ & $20.24 \pm 0.06$ & $14.26 \pm 0.03$ & $6.35 \pm 0.07$ & $1.20 \pm 0.03$ & $0.05 \pm 0.01$ & & & & & & & & & \\
\hline \multirow{2}{*}{$\mathrm{SCU}$} & $\begin{array}{l}\text { Kjeldahl } \\
\text { method }\end{array}$ & $36.8 \pm 0.5$ & $33.5 \pm 0.3$ & $30.3 \pm 0.5$ & $27.3 \pm 0.7$ & $26.3 \pm 0.4$ & $23.6 \pm 0.6$ & $22.4 \pm 0.2$ & $20.6 \pm 0.4$ & $18.3 \pm 0.7$ & $16.0 \pm 0.4$ & $11.8 \pm 0.5$ & $6.3 \pm 0.7$ & $4.1 \pm 0.6$ & $3.1 \pm 0.1$ & $1.8 \pm 0.2$ & $0.7 \pm 0.01$ & $0.0 \pm 0.0$ \\
\hline & $\begin{array}{c}\text { HPLC } \\
\text { method }\end{array}$ & $37.11 \pm 0.02$ & $34.03 \pm 0.04$ & $30.91 \pm 0.01$ & $28.09 \pm 0.05$ & $26.87 \pm 0.02$ & $24.23 \pm 0.03$ & $22.79 \pm 0.06$ & $21.12 \pm 0.02$ & $18.96 \pm 0.05$ & $16.48 \pm 0.08$ & $12.69 \pm 0.04$ & $7.05 \pm 0.02$ & $4.45 \pm 0.03$ & $3.27 \pm 0.01$ & $1.99 \pm 0.04$ & $0.77 \pm 0.05$ & $0.05 \pm 0.01$ \\
\hline
\end{tabular}

The Kjeldal method for determination of nitrogen content involves three major steps of digestion, distillation and titration. For digestion, the urea sample was mixed with sulfuric acid at high temperatures. The digested sample was then allowed to cool down to the room temperature, diluted with water and transferred to the distillation unit. During the distillation, the alkaline solution was added to convert ammonium ions into ammonia and transferred into the receiver vessel which filled with aqueous boric acid. The boric acid solution captured ammonia, forming solvated ammonium ions. Finally, the concentration of the captured ammonium ions was determined using titration using standard solution of sulfuric acid.

The percentage of nitrogen content is calculated using the equation below:

$\%$ Nitrogen $=\frac{(\mathrm{ml} \text { boric acid }-\mathrm{ml} \text { blank }) \times \mathrm{N} \text { of acid } \times 1.4007}{\text { weight of sample in grams }}$ 